\title{
O FINANCIAMENTO COMO RECURSO FUNDAMENTAL DAS POLÍTICAS CULTURAIS
}

Alberto Freire albfreire@uol.com.br

Por meio da cultura é possível se vislumbrar diversas ações transformadoras que alcançam os indivíduos e as sociedades dos mais diversos tamanhos e complexidades. Para os indivíduos, vale ressaltar, a ação transformadora da cultura está presente em suas experiências cotidianas com o mundo que o cerca e, também, do contato com as representações estéticas que pertencem ao criativo universo artístico. Já para os grupos sociais diversos, desde a mais singela localidade até países, a cultura representa perspectivas múltiplas como fator para se desenvolverem, considerando-se o desenvolvimento com uma noção ampliada, para além do crescimento econômico.

Na contemporaneidade, a participação da cultura na economia tem desempenhado um papel ascendente em todas as partes do mundo. Conforme estimativas do Banco Mundial, as atividades culturais situam-se 
na cifra de 7\% do PIB global. Este percentual representa valores consideráveis, em milhões de dólares, embora haja uma concentração privilegiada na produção e consumo do entretenimento.

No caso brasileiro, os números do IBGE indicam a existência de 320 mil empresas ligadas ao setor cultural, que representa 5,7\% do conjunto de empresas do país e produzem 1,6 milhão de empregos formais, conforme divulgado pelo Ministério da Cultura (MinC), em 2008. A inconstância no fornecimento dos dados culturais no país é um problema que compromete o planejamento das políticas culturais e a reflexão e análise dos seus impactos na sociedade. No entanto, em que pese a defasagem, os números dão uma dimensão da relevância que as atividades associadas à cultura representam para a economia.

Por meio da interpretação destes números pode-se deduzir como a cultura desempenha um setor estratégico para se pensar em desenvolvimento, o que faz o Estado e a iniciativa privada aumentarem o seu interesse pelo campo da cultura em suas várias dimensões. Mas a formulação e execução de uma política cultural democrática e abrangente necessitam de vários recursos para se alcançar os objetivos. Recursos que podem ser humanos, legais, materiais e financeiros, conforme aponta Rubim (2007).

No aspecto do financiamento, a histórica classificação da cultura como assessória em relação a outras áreas de atuação do Estado, como saúde, segurança e economia, por exemplo, coloca o investimento financeiro em cultura, ou a sua falta, como uma questão essencial para sua compreensão.

No atual cenário da forte relação entre o mercado e o campo cultural algumas análises enquadram, incorretamente, o modelo de financiamento empresarial como mecenato. Esta é uma apressada assimilação com o financiamento e apoio às artes que vigorou em 
Roma, no império de Augusto César, no período de 30 a.C. a 10 d.C, denominado mecenato. Sua origem como proteção à classe artística está ligada ao político romano Caio Mecenas, que exerceu importante cargo na hierarquia do Império.

Com muita habilidade, Mecenas influenciou o imperador a empreender uma política de apoio às artes, com uma estratégia que incluía uma relação de proximidade entre o governo e a cultura, representada por artistas e pensadores de então. Com esta atuação, Mecenas passou para a história como o "protetor das artes". No entanto, sua estratégia ultrapassa o sentido de proteção artística e se insere, também, na perspectiva de associar reconhecimento e prestígio do Império perante a sociedade. A atuação de Caio Mecenas, ao utilizar a cultura e o pensamento como ações de governo pode ser considerada como um dos mais sutis sistemas para legitimar o poder e foi utilizado, séculos depois, por outros governantes ao longo da história, conforme demonstra Almeida (1994).

Além de governos, outros setores da sociedade também adotaram uma postura de estímulo e proteção às manifestações artístico-culturais. Desde então, o mecenato passou a designar a atitude do Estado, nobreza, Igreja e burguesia de proverem a manutenção de artistas e fomento à atividade cultural como símbolo de uma política de apoio material e/ou financeiro, com forte atuação na Europa renascentista. Podemos classificar este modelo como a configuração da gênese do financiamento cultural por parte do Estado.

Essa forma de acumular prestígio por meio da manutenção e custeio da produção cultural se estendeu, ao longo do tempo, e chegou ao século XX marcado pela individualidade dos grandes capitalistas norte-americanos como mantenedores de artistas individuais e instituições ligadas à cultura. Personalidades como Henry 
Ford, John Rockfeller, Peggy Guggenheim e Andrew Carnegie são exemplos citados de forma recorrente como empreendedores do moderno mecenato. Beneficiados pela legislação liberal americana, os industriais podiam fazer doações individuais, ao passo que suas empresas eram proibidas de fazê-lo. A aquisição de coleções artísticas e o apoio a bibliotecas e instituições de ensino constituíram a base do modelo de mecenato realizado nos Estados Unidos.

A história brasileira conta com alguns exemplos de empresários que exerceram o papel de mecenas. Os nomes mais expressivos são Assis Chateaubriand e Francisco Matarazzo, importantes colecionadores de obras de arte que deixaram um importante patrimônio de contribuição à cultura artística. Instituições importantes como o Museu de Arte de São Paulo (MASP) e o Museu de Arte Moderna de São Paulo (MAM), representam o legado do mecenato exercido por esses dois capitalistas a partir da metade do século XX.

O percurso do apoio às artes e à cultura, desde a época de Caio Mecenas, apresenta como pano de fundo a trajetória dos poderes vigentes. As transformações históricas que ocorreram no mecenato e em outras formas de financiamento cultural, ao longo do tempo, foram resultado das mudanças ocorridas nas relações de poder e, consequentemente, na relação entre o poder político e a cultura. (VAZ, 2003)

Ao analisar a organização e o financiamento da cultura em uma perspectiva histórica, desde a concepção de Caio Mecenas, no Império Romano, até a contemporânea forma de patrocínio cultural, Albino Rubim (2005, p. 55) registra as mudanças ocorridas, partindo de uma vinculação exclusiva com o Estado, até chegar ao modelo da contemporaneidade e registra que "[...] tais mudanças implicaram uma maior complexidade da organização e financiamento da cultura".

\section{O Financiamento como recurso fundamental...}




\section{O financiamento contemporâneo}

É própria da atividade cultural a necessidade de ser materializada e disponibilizada para o consumo e fruição. Neste estágio, o aporte de recursos diversos torna-se imperativo. É nesse instante que se revela como indispensável a atuação de uma instituição ou indivíduo que promova o financiamento. Assim, a produção artístico-cultural coloca em contato a figura do criador, que se expressa por diversos meios e linguagens, e o agente do financiamento, que propicia a chegada do produto cultural ao mercado dos bens simbólicos. Mas para além da cultura artística, outras práticas e modos de produção culturais também carecem do financiamento, em suas várias faces e modelos, para se realizarem como uma prática social.

Desta forma, o campo cultural é financiado por várias fontes, que podem ser públicas, das diversas esferas, e também pela iniciativa privada, caracterizada por empresas, fundações e outros segmentos da sociedade civil. As formas como entes públicos e privados se relacionam são fatores fundamentais para a caracterização dos mecanismos de financiamento da cultura e o entendimento do lugar que esse financiamento ocupa em uma determinada realidade social.

Em artigo intitulado A educaşão e a cultura nas constituições brasileiras, Alfredo Bosi (2004) aponta o tratamento genérico dispensado ao patrimônio simbólico pelo Estado brasileiro, tanto no Império, na constituição de 1824, como na República, em 1891. A presença do Estado na cultura só foi incluída a partir da Constituição Federal de 1934, o que reforça a importância que esta passou a ter como um tema de interesse republicano para a nova ordem, representada por Getúlio Vargas. A partir de então, a União, os estados e os municípios ficaram constitucionalmente autorizados a "favorecer e animar" o desenvolvimento das ciências, das artes, 
das letras e da cultura em geral. Após 1934, portanto, o texto constitucional inseriu o fomento à cultura como uma obrigação, o que foi mantido nas constituições federais posteriores, ultrapassando o favorecimento e a animação.

A atuação do Estado na cultura tem aspectos políticos e ideológicos que são relevantes e norteadores para os estudos e análises de política cultural. Orientações governamentais de poder distintas, sejam autoritárias ou democráticas, têm acentuados reflexos no trato com o campo cultural. Dessa forma, os objetivos das ações culturais originadas no Estado trazem sempre esses componentes, que interferem no modelo de financiamento público executado pelo Estado. ${ }^{1}$

No Brasil, enquanto a Constituição Federal de 1988 deu um importante passo nas garantias do compromisso do Estado com a cultura, as fontes de financiamento público não foram explicitadas, de acordo com Dória (2003). Em nosso país, o Estado é, historicamente, o responsável principal pelo financiamento da cultura, uma tradição que não difere muito de outras nações. O modelo de investimento de recursos públicos se caracteriza como financiamento direto. Englobam-se nesse segmento as verbas dos orçamentos do Ministério da Cultura (MinC) e seu conjunto de instituições com objetivos definidos de aplicação dos recursos financeiros para execução da política cultural, utilizando os mecanismos de financiamento oriundos do Estado. (SILVA, 2007)

O financiamento indireto constitui os investimentos em cultura cuja origem esteja fora do Estado. Nesse âmbito estão incluídas as pessoas físicas, um segmento ainda pouco expressivo em volume de recursos destinados à cultura no Brasil e as empresas com histórico de presença marcante há pouco mais de duas décadas, 
com criação das leis de incentivo e a renúncia fiscal permitida pelo governo.

A destinação de recursos para a cultura não é essencialmente uma novidade no mundo empresarial, embora na década de 1990 tenha ocorrido um crescimento dessa relação entre empresas e as produções do campo cultural no Brasil, trajetória que resultou da diminuição da presença do Estado como ente fundamental do financiamento da cultura em suas várias vertentes como o patrimônio, as artes, o entretenimento e outros segmentos.

As razões apontadas para a redução da presença do Estado na cultura são várias. Alguns autores, como Ramos (2002), indicam a falência financeira do Estado como fator determinante. Este argumento tem características típicas do ideário neoliberal. O discurso do neoliberalismo fortaleceu-se, sobretudo nos anos 1990, com a defesa da liberdade para os mercados atuarem em vários setores, reservando ao Estado funções reduzidas, nas quais a cultura não se incluía.

Outros autores, como Vanucchi (2002) e Eagliton (2005), indicam a redução do tamanho das administrações públicas em esfera global e a consequente transferência de muitas atribuições para o mercado, o que configurou uma das características mais marcantes do pensamento neoliberal. Os resultados obtidos com o enfraquecimento da presença do Estado em vários setores foram, muitas vezes, desastrosos, reafirmando que o modelo e o seu discurso repetido à exaustão eram equivocados como fórmula para desenvolver países e outros territórios de tamanhos e complexidades diversas.

Nesse cenário, o segmento empresarial aproximou-se do campo da cultura e passou a exercer forte presença como agente de financiamento e apoio, sobretudo das produções artísticas e 
do entretenimento. Essa interação não se deu por altruísmo do empresariado. A associação tem objetivos claros e definidos, que podem ser resumidos na perspectiva de se obter maior participação no mercado consumidor, utilizando a cultura como estratégia de comunicação para fortalecimento da imagem das organizações empresariais, seus produtos e serviços.

Com o propósito de criar distinção em um cenário comercial cada vez mais competitivo e de produtos semelhantes, a atividade de marketing estabelece novas estratégias para posicionar as empresas no mercado. Com esse fim, surgiram várias derivações do markeing, segmentadas por área de interesse e atuação como o esportivo, ambiental, social etc. O marketing cultural, portanto, situa-se neste contexto. Trata-se de um fenômeno contemporâneo, pelo qual a diferenciação das empresas ganhou relevância publicitária, competindo, em certa medida, com a publicidade dos produtos ou serviços colocados à disposição dos consumidores.

Assim, neste modelo de comunicação e negócios busca-se associar a ideia da qualidade do produto à confiabilidade de quem produz. Para dar visibilidade ao produtor foram incorporadas ações que, em geral, têm pouca ou nenhuma relação com o negócio empresarial. Nesta perspectiva, organizações do setor industrial, de serviços, alimentos, energia, petróleo etc. incorporam nos seus planos estratégicos ações que podem ser exploradas pelas várias vertentes do marketing.

O entendimento do significado do que seja marketing cultural desfaz a ideia, muito difundida, de que há um mecenas no comando de cada organização que utiliza este mecanismo de financiamento à cultura. No entanto, a associação entre empresas e a cultura no campo mercadológico remete à atividade do marketing que tem na troca as suas bases. O investimento de recursos financeiros ou materiais para a produção cultural reverte-se em oportunidade 
de construção e reforço da imagem e marca das organizações, o que configura o sentido da estreita relação entre o mundo empresarial e o campo da cultura. Afinal, nas relações cotidianas dos negócios, as empresas fazem trocas e não doações, conforme Muylaert (2000).

No financiamento promovido por empresas para viabilizar ações do campo da cultura, via marketing cultural, vigora a noção de patrocínio, uma forma clássica que relaciona um doador de recursos e um beneficiário, responsável pelo projeto cultural. A ação de patrocínio configura-se, também, como uma forma de troca. A legislação brasileira, por meio da Lei Rouanet, inclusive, reconhece e valida este modelo, na medida em que regula e permite ao patrocinador utilizar a publicidade para tornar explícito o investimento em cultura.

O mecanismo de incentivos fiscais da Lei $n^{\circ}$ 8.313/1991, a Lei Rouanet, é uma forma de inserir a iniciativa privada ao setor cultural. Por meio desta Lei o produtor apresenta uma proposta cultural ao Ministério da Cultura (MinC) e, caso seja aprovada, é autorizado a captar recursos para o financiamento junto a pessoas físicas ou empresas. Os incentivadores que apoiarem o projeto poderão ter total ou parte do valor investido deduzido do imposto a pagar. (BRASIL, 2011)

Nesta modalidade de financiamento as trocas são mais explícitas, numa clara relação de mercado, onde se investe com a perspectiva de obtenção de retorno de natureza diversa, seja do aumento de prestígio e reconhecimento que se enquadra no campo do simbólico, ou mesmo com o aumento no faturamento e nos lucros, pertencente ao campo material e tangível.

$\mathrm{Na}$ comparação entre financiamento do Estado e do mercado para a cultura, uma diferença visível se constata na mensuração 
dos resultados. Na atuação do Estado os ganhos são para a coletividade, considerando-se relevantes a produção, o acesso e o consumo cultural como fatores determinantes para a dinâmica da transformação de uma sociedade.

Já no financiamento indireto, concedido pelas empresas, os objetivos mudam e os resultados esperados direcionam-se, quase exclusivamente, para a organização financiadora. As tensões entre o financiamento público e privado se explicitam de forma bastante claras nos dois modelos.

Para Ana Carla Reis, pelas diferenças existentes entre o financiamento público e privados, eles podem ser separados em critérios distintos que demarcam o lugar ocupado por cada um na ação de disponibilizar recursos para a cultura. Segundo a autora, a compreensão dessas duas fontes de financiamento passa pela análise de critérios como motivações, públicos, objetivos, mensuração de resultados e articulações. O quadro a seguir, sintetiza as diferenças fundamentais indicadas pela autora.

O quadro apresentado pela autora oferece um plano geral das diferenças existentes nos modelos de financiamento público e privado. No seu conjunto, os itens listados deixam claros como o Estado e o mercado se guiam por caminhos distintos quando se envolvem na atribuição de financiar a cultura.

Além da dupla relação entre o público e o privado como entes que financiam a cultura, há também que considerar o autofinanciamento, oriundo da receita gerada pela exibição e comercialização das produções culturais. No entanto, esta terceira modalidade tem uma presença minoritária no cenário das artes e do entretenimento no Brasil. 


\begin{tabular}{|c|c|c|}
\hline & Setor Público & Setor Privado \\
\hline Motivação & Social & $\begin{array}{l}\text { Social ou pessoal } \\
\text { (mecenato) e comercial } \\
\text { (patrocínio). }\end{array}$ \\
\hline Público-Alvo & População em geral & $\begin{array}{l}\text { Consumidores/clientes } \\
\text { atuais, ou potenciais, } \\
\text { fornecedores, funcioná- } \\
\text { rios, governo, formadores } \\
\text { de opinião, jornalistas, } \\
\text { comunidades, etc. }\end{array}$ \\
\hline Objetivo & $\begin{array}{l}\text { Os estabelecidos na } \\
\text { política cultural: demo- } \\
\text { cratização, diversidade, } \\
\text { promoção da identidade } \\
\text { nacional, etc. }\end{array}$ & $\begin{array}{l}\text { Pessoais ou sociais (mece- } \\
\text { nato) ou estabelecidos na } \\
\text { estratégia de comunicação: } \\
\text { divulgação da marca, apri- } \\
\text { moramento da imagem, } \\
\text { endomarketing, promoção } \\
\text { junto a segmentos, etc. } \\
\text { (patrocínio). }\end{array}$ \\
\hline $\begin{array}{l}\text { Forma de } \\
\text { mensuração } \\
\text { dos resulta- } \\
\text { dos espera- } \\
\text { dos }\end{array}$ & $\begin{array}{l}\text { Eliminação das desigual- } \\
\text { dades de acesso à cultura, } \\
\text { distribuição descentrali- } \\
\text { zada dos projetos e } \\
\text { instituições culturais, } \\
\text { estudo de imagem do } \\
\text { país, aquecimento da } \\
\text { economia local, etc. }\end{array}$ & $\begin{array}{l}\text { Cobertura de mídia, } \\
\text { levantamentos de conhe- } \\
\text { cimento da marca, estudos } \\
\text { de imagem, predisposição } \\
\text { à compra, aprovação de } \\
\text { projetos etc. }\end{array}$ \\
\hline Articulação & $\begin{array}{l}\text { Setores econômico, } \\
\text { social, educacional, } \\
\text { tecnológico, de relações } \\
\text { exteriores, etc. }\end{array}$ & $\begin{array}{l}\text { Com a comunidade } \\
\text { (mecenato) ou com a } \\
\text { estratégia de comunicação } \\
\text { da empresa (patrocínio). }\end{array}$ \\
\hline
\end{tabular}

Quadro 1 - Setor público e privado no financiamento da cultura Fonte: Reis (2006, p. 152). 
O financiamento da cultura no segmento da receita direta é uma especificidade que se observa na produção da indústria cultural. Em um país como o Brasil, de históricas dificuldades socioeconômicas de maioria da população, o modelo de autofinanciamento pela receita direta, sem outras fontes de recursos, é considerado de pouco resultado pelos realizadores de projetos culturais.

A solução, conforme argumentam os produtores, é a participação do Estado como forma de viabilizar os projetos, ou a busca de recursos nas empresas. Os altos custos de produção, em geral, dificultam a produção de projetos com recursos próprios neste segmento. Por outro lado, o marketing cultural das empresas dedica uma preferência estratégica às artes e o entretenimento pela evidente possibilidade de associação e exibição das suas marcas em espetáculos com potencial atração de público.

A transferência de recursos para a produção cultural tem sutilezas que, em geral, não são percebidas pelo público a quem se destina o espetáculo, ou projetos culturais. Eles apenas veem as marcas nas peças publicitárias sem uma maior compreensão do que significa patrocínio, apoio, realização etc. A relação abaixo apresenta uma síntese do significado de cada uma dessas modalidades de participação empresarial em um projeto de cultura, conforme Vaz (2003) e Reis (2006).

\section{Doação}

Transferência financeira ou de bens, mas sem uso permitido da publicidade, marca ou nome da empresa doadora.

\section{Patrocínio}

Destinação de recursos para viabilizar a execução de um projeto cultural, com fins promocionais. Neste caso a lei permite a exibição das marcas patrocinadoras. 


\section{Apoio}

Não envolve recurso financeiro. O patrocinador contribui, exclusivamente, com bens e serviços.

\section{Promoção}

Quando a empresa está ligada ao setor de comunicação e se encarrega de promover o projeto cultural em seus veículos.

\section{Realização}

O realizador é o produtor, ou seja, quem idealiza e executa o projeto cultural.

As discussões e análise sobre o processo de financiamento à cultura no Brasil, geralmente se voltam para a distinção existente entre financiamento público e privado. Com a utilização das leis de incentivo, principalmente a Lei Rouanet, as fronteiras que separam o público e o privado são tênues. Neste modelo, o patrocínio cultural se inicia nos departamentos de marketing das empresas, passa pelo Ministério da Cultura, e termina no Ministério da Fazenda, com a compensação entre os valores investidos em cultura com os impostos a pagar, o que configura um financiamento público com o rótulo de privado.

$\mathrm{Na}$ iminência de passar por transformações articuladas pelo Ministério da Cultura, a lei de incentivo federal reacendeu as discussões sobre os seus méritos e defeitos para o financiamento cultural no país. Com o rótulo de nova Lei da Cultura, a atualização do aparato legal para política cultural brasileira tramita no Congresso e traz propostas de alterações com o objetivo de dar conta das novas exigências da sociedade na busca de recursos diversos para a produção cultural, sobretudo o financiamento.

As discussões, no entanto, não são isentas de tensões. De um lado estão os que defendem a continuidade da Lei Rouanet nos moldes 
em que se encontra. Para este segmento, a decisão sobre o que deve ou não ser patrocinado deveria permanecer no mercado, ou seja, nos departamentos de marketing das empresas. No entendimento deste grupo, a permanência do modelo evitaria o que rotulam de "dirigismo cultural", ou seja, o Estado ter a prioridade de decidir como e onde serão investidos os recursos destinados à cultura. Este segmento tem fortes ligações com a produção de grandes espetáculos, situa-se nos grandes centros urbanos do país e sinaliza que o conceito de cultura está associado à arte, ao entretenimento e aos espetáculos com alto potencial de retorno dos investimentos.

Do outro lado encontra-se o segmento defensor de que aquelas produções com poder de sustentabilidade, por meio da venda de ingresso ou produtos culturais, não deveriam obter prioridade das verbas públicas incentivadas. Neste caso, a compreensão de cultura mostra-se mais ampliada, centrada no acesso mais democrático e que reflita a diversidade cultural brasileira em todas as suas amplas definições e noções, que pode ir da arte ao modo de vida e o desenvolvimento, para citar apenas três das inúmeras possibilidades de se conceber a cultura.

\section{Consideraçōes Finais}

O financiamento da cultura apresenta diversos mecanismos utilizados para criar as condições de se conceber e realizar projetos culturais. Diante disso, as fontes de financiamento são elementos de destaque desde os mais remotos tempos históricos, quando o campo cultural reafirmou sua relevância na sociedade. O mecenato, por exemplo, se configurou como uma pioneira intervenção do Estado, Igreja e burguesia europeia, que por motivos diversos, faziam aporte de recursos para os artistas da época, ou os acolhiam 
em seus castelos e propriedades, com o propósito de fruir as criações de modo privado e incorporar a riqueza e a representação estética dos bens simbólicos ao patrimônio dos bens materiais, já devidamente acumulados.

$\mathrm{Na}$ contemporaneidade, novos sujeitos exercem o papel que no passado fora exercido pelos mecenas, mas com outros objetivos. O Estado, as empresas, as pessoas físicas e organizações diversas figuram como responsáveis diretos ou indiretos pelo investimento de recursos financeiros e de outra natureza em cultura. Assim, o financiamento cultural apresenta características distintas, baseadas, dentre outros aspectos, na forma como o Estado atua para fomentar a produção simbólica e, também, como regula a participação da sociedade civil neste importante segmento das políticas culturais.

No Brasil, após as leis de incentivo fiscais, houve uma marcante transferência no papel do financiamento à cultura, do Estado para as empresas. Desde então, o mercado passou a exercer uma representação significativa para a realização das atividades culturais, embora os recursos sejam predominantemente públicos. Nesse momento, o marketing cultural, uma atividade que no passado era incipiente nas organizações, se consolidou de forma consistente. A atuação das empresas, associando imagem e marca com o campo da cultura, provocou mudanças que reconfiguraram o sistema de financiamento cultural. O aparente esgotamento desta forma de financiamento, por não cumprir os objetivos de democratização e acesso aos bens culturais, revelou a necessidade de se aprofundar o debate, as análises e reflexões na perspectiva de se configurar não apenas uma nova lei, mas mudanças estruturais na política cultural brasileira.

O financiamento ocupa um lugar privilegiado para a formulação e execução das políticas culturais com origem no Estado, no mer- 
cado ou em outras instâncias da sociedade civil. Recursos diversos são acionados (RUBIM, 2007) para a concepção de políticas que tenham em seus objetivos a promoção do desenvolvimento e da inclusão social, por meio do universo simbólico que caracteriza o campo cultural. Desta forma, os recursos financeiros e os mecanismos de disponibilizá-los representam papel fundamental nas várias etapas que caracterizam a produção de bens culturais.

Essa perspectiva de se pensar a cultura como estratégia de desenvolvimento e cidadania, por meio de uma política cultural abrangente, pode se configurar como uma síntese para a expressão política cultural. Nesse sentido é possível planejar e colocar em prática as ações que pertencem ao domínio da política, tendo a cultura como a base de referência para executar as transformações necessárias que conduzam ao crescimento de uma sociedade. Assim, se a ideia de reformar remete à volta para a forma inicial, transformar, ao contrário, indica transpor a forma original para se conceber uma nova forma. Afinal, a concepção do novo é um estado permanente do campo da cultura.

\section{Notas}

${ }^{1}$ Para a noção e delimitação de público e privado na política cultural ver Barbalho (2005).

\section{Referências}

ALMEIDA, José Mendes de. A arte é capital: visão aplicada do marketing cultural. Rio de Janeiro: Rocco, 1994.

BARBALHO, Alexandre. Política Cultural. In: RUBIM, Linda (Org.) Organização e produção da cultura. Salvador: Edufba, 2005. p. 33-52. 
BOSI, Alfredo. Plural mas não caótico. In: BOSI, Alfredo (Org.). Cultura brasileira: temas e situações. 4. ed. São Paulo: Editora Ática, 2004. p. 7-15.

BRASIL. Ministério Da Cultura. Projetos culturais via renúncia fiscal. 2011. Disponível em: < http://www.cultura.gov.br/site/2011/07/07/projetosculturaisvia-renuncia-fiscal/>. Acesso em: jul. 2011.

DÓRIA, Carlos Alberto. Os federais da cultura. São Paulo: Biruta, 2003.

EAGLETON, Terry. A idéia de cultura. Tradução de Sandra Castello Branco. São Paulo: Editora Unesp, 2005.

FREIRE, Alberto. Explorando em outros campos: a trajetória da Petrobrás na cultura brasileira. 2010. 260f. Tese (Doutorado em Cultura e Sociedade). Faculdade de Comunicação, Universidade Federal da Bahia, Salvador, 2010.

MILLER, Toby; YÚDICE, George. Política cultural. Barcelona: Gedisa, 2004.

MUYLAERT, Roberto. Marketing cultural e comunicação dirigida. 5. ed. São Paulo: Globo, 2000.

RAMOS, Daniela. Patrocínio cultural em Minas Gerais: análise quantitativa das empresas investidoras em cultura via lei estadual de incentivo - 1998-2001. Belo Horizonte: Fundação João Pinheiro. Centro de Estudos Históricos e Culturais, 2002.

REIS, Ana Carla Fonseca. O financiamento da cultura: teoria e prática em um estudo internacional comparado. São Paulo: Thomson, 2006.

RUBIM, Antonio Albino Canelas. Marketing cultural. In: RUBIM, Linda. (Org.) Organização e produção da cultura. Salvador: Edufba, 2005. p. 53-77.

. Políticas culturais: entre o possível e o impossível. In:

NUSSBAUMER, Gisele. Teorias e políticas da cultura: visões multidisciplinares. Salvador: EDUFBA, 2007. p. 139-158.

SILVA, Frederico A. Barbosa da. Economia e política cultural: acesso, emprego e financiamento. Brasília: Ministério da Cultura, 2007.

VANUCCHI, Aldo. Cultura brasileira: o que é, como se faz. 3. ed. São Paulo: Loyola, 2002.

VAZ, Gil Nuno. Marketing institucional: o mercado de idéias e imagens. 2. ed. São Paulo: Thomson, 2003. 
